\title{
Analisis Minat Siswa terhadap Pembelajaran Fisika Kelas X MIPA di SMAN 4 Kota Jambi
}

\author{
Haini Safitri*, Dinda Febrina Alvita, Elfrida Desya Novista \\ Pendidikan Fisika, Universitas Jambi, Indonesia \\ *hainisafitri@gmail.com
}

\begin{abstract}
Abstrak
Penelitian ini bertujuan untuk menganalisa bagaimana minat siswa terhadap pembelajaran fisika dan untuk mengetahui kategori minat siswa terhadap pembelajaran fisika. Penelitian ini menggunakan metode deskriptif kuantitatif, yang dimana melalui pembagian instrument penelitian berupa angket minat pembelajaran fisika secara online dengan menyebarkan angket menggunakan google form. Sampel yang diteliti merupakan siswa kelas X MIPA SMA Negeri 4 Kota Jambi yang berjumlah 65 orang. Sikap siswa dalam penlitian ini menggunakan uji Likert. Data dalam penelitian ini diolah dengan menggunakan aplikasi pengolah data yaitu SPSS. Berdasarkan data yang telah diperoleh dapat ketahui bahwa minat siswa terhadap pembelajaran fisika terkategori baik dengan persentase $57 \%$ dari 65 siswa memiliki tanggapan yang baik terhadap pembelajaran fisika. walaupun masih terdapat persentase $30,7 \%$ yang memiliki kategori tanggapan tidak baik terhadap pembelajaran fisika. hal ini menunjukkan siswa kelas X MIPA di SMA Negeri 4 Kota Jambi lebih dominan memiliki tanggapan baik terhadap pembelajaran fisika dilihat dari persentase pengisian angket minat.
\end{abstract}

Kata kunci: analisis, minat siswa, pembelajaran fisika.

Dikirim: 03 November 2020

Direvisi: 02 Maret 2021

Diterima: 11 Agustus 2021

Identitas Artikel:

Safitri, H., Alvita, D. F., \& Novista, E. D. (2022). Analisis Minat Siswa terhadap Pembelajaran Fisika Kelas X di SMAN 4 Kota Jambi. Jurnal Ilmu Pendidikan (JIP) STKIP Kusuma Negara, 13(2), 128-134.

\section{PENDAHULUAN}

Pendidikan adalah suatu proses agar peserta didik dapat beradaptasi dengan lingkungan sekitarnya, sehingga dapat terjadi perubahan dalam dirinya sendiri. Sekolah merupakan salah satu lembaga untuk berlangsungnya pembelajaran bagi peserta didik melalui kegiatan belajar dan mengajar antara guru dan siswa (Oktaviana, Jufrida, \& Darmaji, 2016). Pendidikan merupakan salah satu peranan penting dalam upaya pengembangan sumber daya manusia serta hal yang cukup menentukan kemajuan suatu bangsa dan negara, maka dari itu pendidikan adalah factor terpenting dalam menghadapi globalisasi (Situmorang \& Nurrahman, 2019). Menurut Kurniawan, Astalini, dan Kurniawan (2019) Pendidikan juga merupakan bagian dari tingkatan setiap individu di suatu bangsa. Kemajuan dari suatu bangsa dapat ditentukan dari keberhasilan pendidikannya. Menurut Saputra, Hendri, dan Aminoto (2019) banyak faktor yang terlibat dalam proses belajar dan pembelajaran yakni guru, siswa, bahan ajar atau materi, fasilitas maupun lingkungan. Proses pembelajaran harus direncanakan terlebih dahulu serta dievaluasi hasilnya, artinya berhasilnya suatu kegiatan pembelajaran banyak 
tergantung pada proses serta hasilnya untuk mencapai dari pembelajaran tersebut. Menurut Dwijayanti dan Pathoni (2016) Strategi dalam proses pembelajaran merupakan peran yang sangat penting, keberhasilan dari pembelajaran tidak luput dari keaktifan siswa dalam mengikuti prosesnya. Partisipasi adalah hal terpenting dalam proses pembelajaran (Khodijah, Hendri, \& Darmaji, 2016) begitupun dengan keaktifan siswa merupakan hal terpenting menunjang keberhasilan proses pembelajaran (Arrasyid, Jufrida, \& Darmaji, 2017). Menurut Dani, Latifah, dan Putri (2019) Pendidikan tidak terlepas dari proses belajar dan pembelajaran.

Sedangkan belajar sendiri yaitu proses yang memperlihatkan perubahan tingkah laku peserta didik. Belajar tentunya membutuhkan minat serta media yang mendukung dalam prosesnya (Estianinur, Astalini, \& Pathoni, 2017). Kebiasaan siswa dalam belajar dipengaruhi oleh lingkungan rumah ataupun lingkungan pergaulannya (Putri, Maison, \& Darmaji, 2018).

Fisika merupakan salah satu mata pelajaran yang penting dalam pembelajaran untuk kehidupan sehari-hari. Menurut Rozana, Jufrida, dan Basuki (2018), fisika dapat dilakukan dengan pembelajaran saintifik yang dimana pembelajaran saintifik tidak hanya melihat hasil akhir namun menitik beratkan pada proses. Kurnia, Hendri, dan Pathoni (2016) Fisika merupakan ilmu yang mempelajari materi dan energy yang terkandung didalamnya berikut dengan kejadian alam dan interaksinya (Suyono, Maison, \& Nehru, 2017). Menurut Setia, Susanti, dan Kurniawan (2017) Fisika ilmu yang bertujuan agar dapat memiliki pemikiran logis, kritis serta obyektif dalam penyelesaian masalah baik dalam bidang fisika ataupun bidang yang lain serta dalam kehidupan sehari-hari. Maka dari itu, sangat penting untuk mempelajari fiska serta pengaplikasiannya Purwanto, Susanti, dan Hendri (2016). Sebuah pembuktian tentang fenomena dalam fisika dapat menandakan seabstrakan terhadap konsep materi pembelajaran fisika (Anuar, Astalini, \& Jufrida, 2016). Menurut Masyithah, Jufrida, \& Pathoni (2017) fisika merupakan mata pelajaran yang dipenuhi dengan konsep-konsep. Menurut Annisak, Astalini, dan Pathoni (2017) konsep ciri-ciri dari fenomena yang berupa abstrak untuk memudahkan komunikasi serta dapat membuat manusia berfikir.

Mata pelajaran fisika merupakan salah satu mata pelajaran yang cukup tidak disukai oleh peserta didik. Kebanyakan disebabkan karena kesulitan siswa dalam pengaplikasian rumus-rumus dalam perhitungan. Itu berarti, siswa yang memiliki kemampuan yang perhitungan atau logika yang tinggi yang mampu memahami fisika (Oktaviana dkk., 2016) dan cukup banyak siswa SMA Negeri se-Kota Jambi yang mengalami kesulitan dalam belajar (Taqwa, Astalini, \& Darmaji, 2015). Asumsi atau tanggapan semacam ini sangat berpengaruh pada minat pembelajaran siswa terhadap mata pelajaran fisika. Siswa yang benar-benar berminat terhadap pembelajaran fisika yang dapat bersungguh-sungguh untuk memahami pembelajaran fisika dan dapat menunjukkan hasil yang baik (Pasaribu, Hendri, \& Susanti, 2017). Fisika merupakan bagian dari ilmu sains sehingga sikap siswa terhadap fisika termasuk dalam sikap terhadap sains (Hardiyanti, Astalini, \& Kurniawan, 2018). Untuk dapat menguasai pelajaran fisika dengan baik maka harus disertai minat siswa terhadap pembelajaran fisika yang cukup tinggi. Oleh karena itu, siswa dengan minat pembelajaran fisika yang tinggi akan mempengaruhi atau meningkatkan hasil pembelajaran fisika dari siswa tersebut. Siswa yang benar-benar berminat terhadap fisika tidak akan merasa fisika adalah pelajaran yang sulit dan akan berusaha untuk menyelesaikan soal-soal yang ada. 
Berdasarkan uraian diatas maka dilakukan penelitian ini yang bertujuan untuk menganalisa sejauh mana minat siswa kelas X MIPA 4, X MIPA 5 dan X MIPA 6 SMA N 4 Kota Jambi terhadap pembelajaran fisika, agar guru-guru atau tenaga pendidik dapa mengetahui bagaimana minat siswa disekolah terhadap pembelajaran fisika untuk keberlangsungan pembelajaran yang lebih efektif.

\section{METODE PENELITIAN}

Metode dalam penelitian ini menggunakan metode deskriptif kuantitatif, yang dimana penelitian ini menggunakan metode dengan instrument berupa angket kepada sampel. Untuk penelitian ini dilakukan di SMA Negeri 4 Kota Jambi, sasaran dari penelitian ini yaitu siswa kelas X MIPA sejumlah 65 siswa. Pengumpulan data dilakukan dengan cara pemberian istrumen berupa angket yang disebarkan melalui google form secara online. Angket ini berupa pernyataan minat tentang pembelajaran fisika.

Analisis sikap siswa terhadap Minat Pembelajaran Fisika dalam penelitian ini meggunakan skala Likert. Skala Likert ini adalah skala dengan jenis skalanya Sangat Setuju, Setuju, Tidak Setuju dan Sangat Tidak Setuju. Setiap peryataan positif dalam instrument memiliki nilai : Sangat Setuju diberi nilai 4, Setuju diberi nilai 3, Tidak Setuju diberi nilai 2 dan Sangat Tidak Setuju diberi nilai 1, sedangkan pada pernyataan negative Sangat Setuju bernilai 1, Setuju bernilai 2, Tidak Setuju bernilai 3 dan Sangat Tidak Setuju bernilai 4. Selanjutnya angket ini berikan kepada siswa kelas X MIPA SMA Negeri 4 Kota Jambi. Hasil data penelitian ini dianalisis mneggunakan aplikasi SPSS. Penelitian menggunakan pendekatan kuantitatif dan dianalis menggunakan statistika deskriptif. Pengelolaan ini bertujuan untuk menganalisis minat siswa terhadap pembelajaran fisika.Khususnya siswa kelas X MIPA berdasarkan indicator sikap yang telah ditentukan.

Hasil data angket minat pembelajaran fisika yang akan dianalisi terdiri dari dua bagian penilaian. Yang pertama adalah penilaian yang didasarkan pada interval: sangat baik, baik, tidak baik, sangat tidak baik. Penilaian ini didasarkan dari frekuensi dan persentase seluruh siswa yang memilih penilaian tersebut. Yang kedua adalah berdasarkan skala sikap. Penilaian ini didasarkan pilihan siswa terhadap skala tersebut yang akan menghasilkan mean, modus, median, standar deviasi, nilai minimum dan nilai maksimum. Kedua penilaian ini akan didapatkan dengan cara menggunakan analsisi statistis deskriptif dengan menggunakan software data aplikasi SPSS.

Selanjutnya untuk klasifikasi angket "Minat pembelajaran Fisika" siswa kelas X MIPA SMA Negeri 4 Kota Jambi, sebagai berikut: (1) Kategori "Sangat Tidak Baik" untuk rentang 15,0-26,25=1,5\%; (2) Kategori "Tidak Baik" rentang 26,26$37,51=30,7 \%$; (3) Kategori "Baik" rentang 37,52-48,77=57\%; (4) Kategori "Sangat Baik" rentang 48,78-60,0=10,8\%.

\section{HASIL DAN PEMBAHASAN}

Berdasarkan penelitian yang telah dilakukan mengenai Minat Pembelajaran Fisika yang dilakukan pada siswa kelas X MIPA SMA Negeri 4 Kota Jambi dengan jumlah responden sebanyak 65 siswa. Setelah data diperoleh lalu dinalisis 
menggunakan SPSS didapatkan nilai mean yaitu 40.18, nilai median yaitu 40.00, nilai modus yaitu 39, nilai standar deviasi yaitu 5.793, selanjutnya nilai maksimumnya yaitu 53, dan nilai minimumnya yaitu 26 .

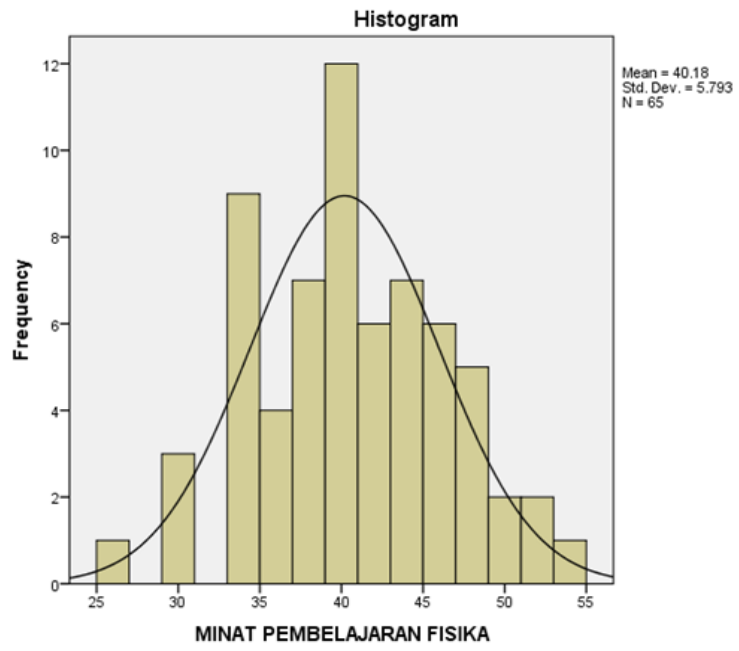

Gambar 1. Grafik Histogram

Dari gambar grafik di atas, dapat dilihat bahwa untuk score 26 didapatkan oleh 1 siswa dengan persentase $1,5 \%$. Score 30 didapatkan oleh 3 siswa dengan persentase $4,6 \%$. Score 33 didapatkan oleh 5 siswa dengan persentase $7,7 \%$. Untuk score 34 didapatkan oleh 4 siswa dengan persentase 6,2\%. Untuk score 36 diperoleh oleh 4 siswa dengan persentase 6,2\%. Untuk score 37 didapatkan oleh 4 siswa dengan persenatse $6,2 \%$. Kamudian score 38 diperoleh oleh 3 siswa dengan persentase 4,6\%. Untuk score 39 diperoleh oleh 6 siswa dengan persentase 9,2\%. Untuk score 40 diperoleh oleh 6 siswa dengan persentase 9,2\%. Selanjutnya, untuk score 41 diperoleh 4 siswa dengan persentase 6,2\%. Untuk score 42 diperoleh oleh 2 siswa dengan persentase 3,1\%. Untuk score 43 diperoleh oleh 4 siswa dengan persentase $6,2 \%$. Untuk score 44 diperoleh oleh 3 siswa dengan persentase 4,6\%. Untuk score 45 diperoleh oleh 5 siswa dengan persentase 7,7. Untuk score 46 diperoleh oleh 1 siswa dengan persentase $1,5 \%$. Untuk score 47 didapatkan oleh 3 siswa dengan persentase 4,6\%. Untuk score 48 diperoleh oleh 2 siswa dengan persentase $3,1 \%$. Untuk score 49 diperoleh oleh 1 siswa dengan persentase 1,5\%. Untuk score 50 diperoleh 1 siswa dengan persentase 1,5\%. Untuk score 51 didapatkan oleh 1 siswa dnegan persentase 1,5\%. Untuk score 52 didapatkan oleh 1 siswa dengan persentase 1,5\%. Terakhir, untuk score 53 didapatkan oleh 1 siswa dengan persentase 1,5\%.

Selanjutnya untuk klasifikasi Minat pembelajaran Fisika siswa kelas X MIPA SMA Negeri 4 Kota Jambi, sebagai berikut.

Tabel 1. Klasifikasi Minat Siswa

\begin{tabular}{ccl}
\hline Interval & Persen & \multicolumn{1}{c}{ Kategori } \\
\hline $15,0-26,25$ & 1,5 & Sangat Tidak Baik \\
$26,26-37,51$ & 30,7 & Tidak Baik \\
$37,52-48,77$ & 57 & Baik \\
$48,78-60,0$ & 10,8 & Sangat Baik \\
\hline
\end{tabular}


Dari hasil data yang telah didapatkan dapat diketahui bahwa minat siswa kelas X MIPA SMA Negeri 4 Kota Jambi terhadap pembelajaran fisika cukup baik karena sebanyak 57\% dari keseluruhan siswa memiliki tanggapan baik terhadap pembelajaran fisika. walaupun terdapat $30,7 \%$ memiliki tanggapan tidak baik, hal tersebut bisa disebabkan karena tingkat kesulitan dari pembelajaran fisika sendiri yang harus memiliki analisa cukup tinggi agar bisa memahaminya atau bisa disebabkan karena minat siswa terhadap pembelajaran fisika yang memang cukup rendah. Berdasarkan studi Supardi, Leonard, Suhendri, \& Rismurdiyati (2015) bahwa siswa yang mimiliki minat belajar tinggi akan cenderung tekun, ulet, semangat dalam belajar, pantang menyerah dan senang menghadapi tantangan. Siswa yang berminat belajar pada kategori tinggi dan gemar terhadap fisika, menjadikan pembelajaran fisika tidak hanya sekedar memenuhi kewajiban dan tugas dari guru atau tuntutan kurikum, tetapi mereka menjadikan belajar fisika sebagai suatu kebutuhan yang ahrus dipenuhi. Bagi mereka, ada atau tidaknya rangsangan dari luar untuk belajar fisika tidak ada bedanya. Minat dalam belajar sangat penting dalam berlangsungnya pembelajaran fisika.

\section{KESIMPULAN}

Berdasarkan penelitian yang telah dilakukan dapat disimpulkan bahwa minat siswa kelas X MIPA SMA Negeri 4 Kota Jambi sudah cukup baik dengan kategori baik rentang 37,52-48,77 dengan persentase $57 \%$ dari jumlah keseluruhan sampel yang diteliti. Hal ini menunjukkan bahwa pembelajaran fisika di SMA Negeri 4 Kota Jambi sudah cukup baik karena tanggapan siswa terhadap pembelajaran fisika juga cukup baik dengan melebihi 50\%. Walaupun terdapat persentase siswa sebanyak 30,7\% dalam kategori tidak baik, informasi ini dapat membantu guru agar menggunakan metode pembelajaran yang mendukung agar dapat memotivasi minat siswa terhadap pembelajaran fisika semakin baik.

\section{REFERENSI}

Annisak, W., \& Pathoni, H. (2017). Desain Pengemasan Test Diagnostik Miskonsepsi Berbasis CBT (Computer Based Test). Edufisika: Jurnal Pendidikan Fisika, 2(1), 1-12. https://doi.org/10.22437/edufisika.v2i01.3939

Anuar, S., \& Astalini, A., Jufrida, J. (2016). Pengembangan Adjustable Single Slit Interference Kit Sebagai Media Pembelajaran Difraksi Cahaya Pada Celah Tunggal Kelas XII IPA. Edufisika: Jurnal Pendidikan Fisika, 1(1), 13-17. https://doi.org/10.22437/edufisika.v1i1.2958

Arrasyid, H., Jufrida, J., Darmaji, D. (2017). Upaya Meningkatkan Aktivitas dan Hasil Belajar Siswa dengan Menggunakan Model Pembelajaran Problem Based Learning Berbantuan Lembar Kerja Siswa pada Materi Kalor dan Perpindahannya Kelas X SMA PGRI 2 Jambi. Edufisika: Jurnal Pendidikan Fisika, 2(2), 60-80. https://doi.org/10.22437/edufisika.v2i02.3910

Dani, R., Latifah, N. A., \& Putri, S. A. (2019). Penerapan pembelajaran berbasis Discovery learning melalui metode talking stick untuk meningkatkan pemahaman konsep gerak lurus. Edufisika: Jurnal Pendidikan Fisika, 4(2), 24-30. https://doi.org/10.22437/edufisika.v4i02.6058 
Dwijayanti, E., \& Pathoni, H. (2016). Penerapan Strategi Pembelajaran Aktif Tipe Peer Lessons Untuk Meningkatkan Aktivitas dan Hasil Belajar Siswa pada Materi Suhu dan Kalor Kelas $\mathrm{X}_{\mathrm{A}}$ di SMAN 8 Kota Jambi. Edufisika: Jurnal Pendidikan Fisika, 1(1), 18-21. https://doi.org/10.22437/edufisika.v1i1.2959

Estianinur, E., Astalini, A., \& Pathoni, H. (2017). Pengembangan Aplikasi Mobile Learning Menggunakan Adobe Flash Professional CS6 Berbasis Android pada Materi Ciri-Ciri Gelombang Mekanik untuk Kelas XI SMA. Edufisika: Jurnal Pendidikan Fisika, 2(2), 1-11. https://doi.org/10.22437/edufisika.v2i02.4054

Hardiyanti, K., Astalini, A., \& Kurniawan, D. A. (2018). Sikap siswa terhadap mata pelajaran fisika di SMA Negeri 5 Muaro Jambi. EduFisika: Jurnal Pendidikan Fisika, 3(2), 1-12. https://doi.org/10.22437/edufisika.v3i02.4522

Khodijah, D. N., Hendri, M., Darmaji, D. (2016). Upaya Meningkatkan Partisipasi dan Hasil Belajar Dengan Menggunakan Model Pembelajaran Kooperatif Tipe Think Pair Share di Kelas XI MIA7 SMAN 1 Muaro Jambi. Edufisika: Jurnal Pendidikan Fisika, 1(2), 46-54. https://doi.org/10.22437/edufisika.v1i2.3429

Kurnia, N., Hendri, M., \& Pathoni, H. (2016). Hubungan persepsi dengan hasil belajar fisika siswa kelas X Mia di SMA negeri 4 Kota Jambi dan sma negeri 11 kota jambi. Edufisika: Jurnal Pendidikan Fisika, 1(2), 55-63. https://doi.org/10.22437/edufisika.v1i2.3430

Kurniawan, D. A., Astalini, A., \& Kurniawan, N. (2019). Analisis sikap siswa terhadap ipa di smp kabupaten muaro jambi provinsi jambi. Curricula: Journal of Teaching and Learning, 4(3), 111-127. http://doi.org/10.22216/jcc.2019.v4i3.4150

Masyithah, D. C., Jufrida, J., \& Pathoni, H. (2017). Pengembangan Multimedia Fisika Berbasis Model Pembelajaran Inkuiri Terbimbing dengan Menggunakan Adobe Flash CS6 pada Materi Fluida Dinamis Untuk Siswa SMA Kelas XI. Edufisika: Jurnal Pendidikan Fisika,2(1), 51-60. https://doi.org/10.22437/edufisika.v2i01.4042

Oktaviana, D., Jufrida, J., Darmaji, D. (2016). Penerapan RPP Berbasis Multiple Intelligences Untuk Meningkatkan Aktivitas Dan Hasil Belajar Fisika Pada Materi Kalor Dan Perpindahan Kalor Kelas X MIA 4 SMA Negeri 3 Kota Jambi. Edufisika: Jurnal Pendidikan Fisika, 1(1), 7-12. https://doi.org/10.22437/edufisika.v1i1.2957

Pasaribu, D. S., Hendri, M., \& Susanti, N. (2017). Upaya meningkatkan minat dan hasil belajar fisika siswa dengan menggunakan model pembelajaran talking stick pada materi listrik dinamis di kelas X SMAN 10 Muaro Jambi. Edufisika: Jurnal Pendidikan Fisika, 2(1), 61-69. https://doi.org/10.22437/edufisika.v2i01.4043

Purwanto, A. E., Susanti, N., \& Hendri, M. (2016). Studi perbandingan hasil belajar siswa menggunakan media phet simulations dengan alat peraga pada pokok bahasan listrik magnet di kelas IX SMPN 12 Kabupaten Tebo. Edufisika: Jurnal Pendidikan Fisika, 1(1), 22-27. https://doi.org/10.22437/edufisika.v1i1.2954

Putri, A. R., Maison, M., \& Darmaji, D. (2018). Kerjasama Dan Kekompakan Siswa Dalam Pembelajaran Fisika di Kelas XI MIPA SMA Negeri 3 Kota Jambi. EduFisika: Jurnal Pendidikan Fisika, 3(2), 32-40. https://doi.org/10.22437/edufisika.v3i02.5552 
Rozana, T., Jufrida, J., \& Basuki, F. R. (2018). Penerapan Model Pembelajaran Poe Untuk Meningkatkan Keterampilan Proses Sains Kelas XI SMAN 11 Jambi. Edufisika: Jurnal Pendidikan Fisika, 3(2), 66-80. https://doi.org/10.22437/edufisika.v3i02.4541

Saputra, W. R., Hendri, M., \& Aminoto, T. (2019). Korelasi Motivasi dan Hasil Belajar IPA Siswa Kelas VIII Di SMP Negeri Se-Kecamatan Jambi Selatan. Edufisika: Jurnal Pendidikan Fisika, 4(1), 36-45. https://doi.org/10.22437/edufisika.v4i01.3996

Setia, M. O., Susanti, N., \& Kurniawan, W. (2017). Pengembangan media pembelajaran dengan menggunakan adobe flash CS 6 pada materi hukum newton tentang gerak dan penerapannya. Edufisika: Jurnal Pendidikan Fisika, 2(2), 42-57. https://doi.org/10.22437/edufisika.v2i02.3963

Situmorang, P., \& Nurrahman, A. (2019). Analisis Perilaku Jujur Siswa dalam Pembelajaran IPA Terpadu Materi Kalor dan Perpindahannya di SMP Negeri 6 Kota Jambi. Jurnal Nalar Pendidikan, 7(1), 71-79. https://doi.org/10.26858/jnp.v7i1.9012

Supardi, S. U., Leonard, L., Suhendri, H., \& Rismurdiyati, R. (2015). Pengaruh media pembelajaran dan minat belajar terhadap hasil belajar fisika. Formatif: Jurnal Ilmiah Pendidikan MIPA, 2(1),71-81. http://dx.doi.org/10.30998/formatif.v2i1.86

Suyono, S., Maison, M., \& Nehru, N. (2017). Pengembangan E-Learning Berbasis Moodle pada Materi Termodinamika di SMA. EduFisika Jurnal Pendidikan Fisika, 2(2), 34-41. https://doi.org/10.22437/edufisika.v2i02.4065

Taqwa, M. R. A., Astalini, A., \& Darmaji, D. (2015). Hubungan Gaya Belajar Visual, Auditorial, dan Kinestetik dengan Hasil Belajar Siswa pada Materi Dinamika Rotasi dan Kesetimbangan Benda Tegar Kelas XI IPA SMAN SeKota Jambi. In Seminar Nasional Universitas Muhammadiyah Purworejo, (pp. 220-227). 